\title{
DE DE GRUYTER OPEN

\section{STUDIES AND RESEARCHES ON MONITORING BY GIS MODELS EXTREME PHENOMENONS IN THE POPULAR CENTER}

\author{
Iustina Lateș ${ }^{1}$, Alexandru - Lucian Luca ${ }^{2}$, \\ Ștefania Chirica ${ }^{1}$, Mihail Luca ${ }^{3}$
}

Key words: database, building classes, hydrants, fire areas

\begin{abstract}
The work involves the realization of a GIS model that includes both information on real estate cadastre and water supply networks. This shows the stages of making such a model, starting from field measurements, to structuring the database and custom layouts. In the study, the distribution pipelines equipped with fire hydrants and the existing building types in the area were considered as the main elements. Buildings were classified according to importance, height, destination, mapping indexes, etc. and have been integrated into the GIS model. GIS programs aim at specifying as much as possible the textual data attached to perform complex analyzes. Autocad and ArcMap programs allow you to get thematic maps on building types, pipeline network analysis on which hydrants are located, and how to protect firewalls. The study model was developed only for a sector in the city of Iaşi, but it can be extended to an application that can be used in other urban areas for the purpose of being used by the water-channel directorate, the intervention teams, the public administration local, etc.
\end{abstract}

\section{Introduction}

Urban and rural centers are affected by a series of disaster phenomena such as fires, earthquakes, landslides, floods, etc.

At present, fires have a high risk factor and their stopping is almost impossible, as the source of the source depends on various factors: unattended fire,

${ }^{1} \mathrm{PhD}$ student Eng., „Gheorghe Asachi” Technical University of Iasi, Faculty of Hydrotechnical Engineering, Geodesy and Environmental Engineering, e-mail lates.iustina90@gmail.com,

${ }^{2}$ Dr.ing., Polias-Instal Company, Iasi, Romania

${ }^{3}$ Engineering, Geodesy and Environmental Engineering, e-mail mluca2004@yahoo.com 
short circuit, road accidents, excessive heat, natural phenomena, etc. Fires spread both in inhabited areas (rural or urban), in vegetation areas, in industrial areas, etc. In the case of fires in the inhabited areas, Ferreira T.M., et al. (2016) identified a number of factors contributing to increased fire risk: flammable materials, high density of buildings that do not keep the minimum construction distance, narrow streets, common walls between adjacent buildings, old electrical installations, etc.

Fires are propagated differently depending on the type of building and location, which requires important changes and requires monitoring using performance models. These models are used to develop fire prevention and improvement strategies on fire safety (Cheng H., Hadjisophocleous G., 2009).

Fires in inhabited areas cause material and material damage. In recent years, their number has increased and the rate of occurrence varies depending on the factors of fire production (Zang X., et all., 2018).

Taking into account that the Romanian cities are in constant evolution and the new constructions are carried out without complying with the norms and laws of fire, but also with the Civil Code, it is important to monitor the inhabited areas. Due to the rapid pace of construction of buildings and the high costs of entry into legality of land and associated buildings, a GIS model of fire monitoring is necessary. For many urban constructions, no data are known about the materials used, the height regime, the owners, the year of construction, etc.

\section{Customization of buildings according to fire characteristics in correlation with building registration}

The registration of constructions takes into account the law 7/1996, and they are integrated into the GIS environment (the application Eterra) based on the measurements made as well as the property acts. Analyzing the information provided by ANCPI Agency, only 30\% of the total number of buildings in Romania are integrated into this application.

Customizing buildings by fire category is important for emergency inspectorates (ISUs), because in the event of fire, knowing the types of buildings and the factors that can influence the evolution of the fire is essential.

a) Classification of buildings in cadastral terms;

Buildings are classified mainly according to their destination. The information attached to the construction differs according to the legal status of the building. Thus, a building with documents will have a unique five-digit cadastral number and building code (Ex: 63398 - C1). If the construction is older, the old cadastral number and the old land registry number will be attached. Also important is the height regime of the building, the field filled in the number of levels section, and in 
the case of blocks of buildings with separate individual units the complete number and the number (Fig.1)

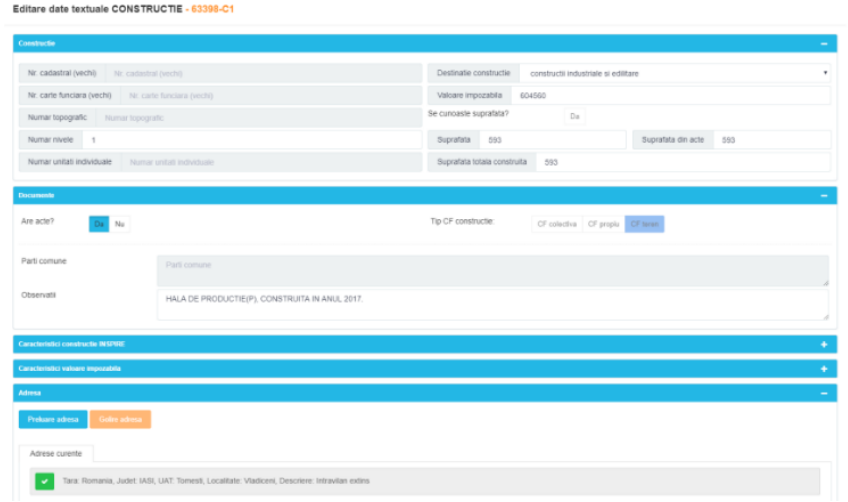

Fig. 1. Visualize textual data attached to constructions in the Eterra program

Depending on the destination of the buildings they are classified in: CAS administrative and social cultural buildings; CA - annexes; CL - housing construction; CIE - industrial and public buildings.

The registration of buildings also need their taxable value, also depending on the number of levels that will be completed and the surface built on the ground as well as the total built-up area unfolded (Fig. 2). The difference between the construction of documents and the documents without papers is that in the case of the latter, the field with the document's surface will not be completed. The constructions have the same address as the site of the site have as description the type of construction, the height regime and the year of their construction.

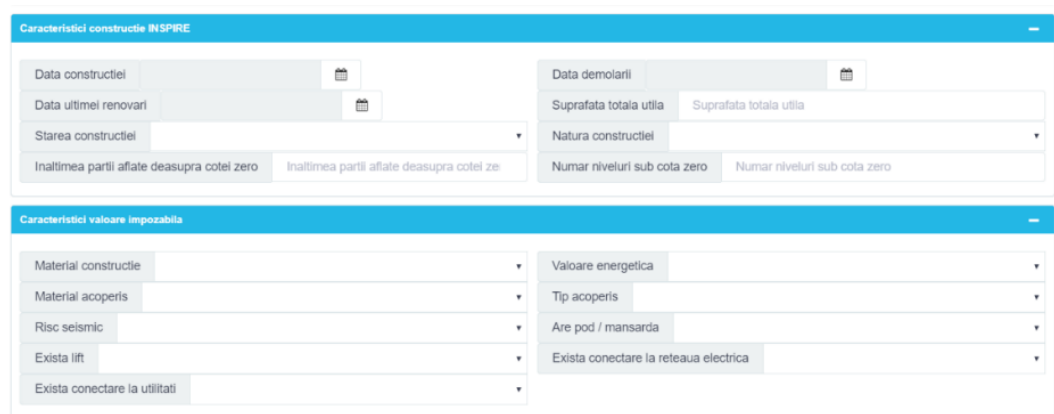

Fig. 2. Visualize additional textual data attached to constructions in Eterra 
b) Classification of buildings according to mapping indexes (Fig. 2) (Hogas I.H., 2015):

- buildings of durable masonry with reinforced or metal reinforced concrete structure and reinforced concrete floors; for these, the mapping index A is used;

- buildings of masonry lift with reinforced concrete slabs in which the index B is used;

- mapping index $\mathrm{C}$ highlights wooden buildings with concrete or stone foundations;

- index D is used for tile, earth or cobblestone buildings;

Charting indexes are usually accompanied by digits indicating the number of floors (the figure from the exponent) and the footer marked with the letter "s". The technical state of maintenance of a building can be classified as: good, good, mediocre (satisfactory), bad, insalubrious, ruined.

c) Classification of buildings according to fire risk (P 118-99, AIIR, Installation Manual, Is, 2002):

- buildings with a very high fire risk (petrol stations, flammable materials);

- buildings with high risk of fire (flammable materials, etc.);

- buildings with medium risk (administrative and social buildings);

- low-risk buildings (residential buildings, adjacent buildings).

d) Classification of buildings according to their height regime (Pestişanu C. et. all., 1996):

- very tall buildings $(\mathrm{S}+\mathrm{P}+\mathrm{E}>20)$;

- tall buildings $(\mathrm{S}+\mathrm{P}+12)$

- medium buildings $(\mathrm{S}+\mathrm{P}+2 \mathrm{E}, \mathrm{P}+6 \mathrm{E})$;

- ground floor buildings $(\mathrm{P}, \mathrm{S}+\mathrm{P})$;

Buildings in any location require access to public utilities. In the rural area, at 2016 , only $30 \%$ of the inhabitants benefit from the connection to the water supply and sewerage network, so the external fire network that has the role of protecting the buildings is missing.

Hydrants are positioned so that they comply with the fire safety concept. „, It includes conditions for the location of buildings and the performance of structures, construction products, building installations and fire protection installations under fire conditions". The distance between hydrants on urban pipeline networks is 100125 m (NP 133-133, P 118-99). Sanitary Plum Manual, 2002). By location, hydrants must cover protected areas, be accessible and provide the required fire extinguishing parameters. According to the norm P 118/2 - 2013 the external hydrant flow rate is $5-101 / \mathrm{s}$, the minimum pressure is 0.7 bar and the diameter is $80-100-150 \mathrm{~mm}$. 


\section{Customize the functions of the pipeline network equipped with hydrants in a neighborhood of Iasi}

Hydrants are hydraulic installations located on pipes to distribute water for fire-fighting. The pipeline also has hydrants for spraying green spaces and watering public spaces. Hydrants have different codes, a unique location and are characterized by constructive and hydraulic parameters.

\begin{tabular}{|c|c|}
\hline \multirow{2}{*}{ Hydrant } & \multirow{3}{*}{$\begin{array}{l}\text { Hydrant ID } \\
\text { - Tehnical parameters } \\
\text { - Emplacement }\end{array}$} \\
\hline & \\
\hline & \\
\hline & $\rightarrow$ Construction \\
\hline & - Hydraulic installation \\
\hline & $\rightarrow$ Technological parameters \\
\hline & $\begin{array}{l}\text {-Fluid } \\
\text {-Work on the system }\end{array}$ \\
\hline
\end{tabular}

Fig. 3. Characteristic layers of hydrants in the GIS model

Each layer for the hydrant network has graphic information attached to the construction and hydraulic features. Data collection on hydrants is collected during the design, installation and operation phase. By developing a GIS model, it is important to have the tables attached to them with other types of important information in the interpretation and query process. In the case study, the pipeline network initially had 14 hydrants. Each hydrant had attached location information, diameter, flow, construction type etc. On the basis of the field studies, information was added regarding the land quota, flow, pressure, material, year of commissioning, photos, performers, works done for their rehabilitation and improvement etc.

Monitoring the parameters of street hydrants is a high concern, especially since the fire rate has been quite high lately. The correct operation of the street hydrants influences the good organization of the Fire Emergency Inspectorate in case of fire. A customized GIS monitoring system for the hydrant network contains a series of information on hydrant location, type, construction parameters, functional parameters, coverage area, hydrant distances, its current state of play, access conditions, time interventions, repairs, etc.

3. Case Study - Analysis of the fire protection and fire-fighting phenomenon for the "Aviation Plateau" area, Iaşi Municipality

The study area is located in the eastern area of Iaşi, called "Aviation Plate" (Fig. 4). For this area a GIS monitoring model was compiled, consisting of 
components of the hydro-cadastral cadastre and components of the real estate cadastre.

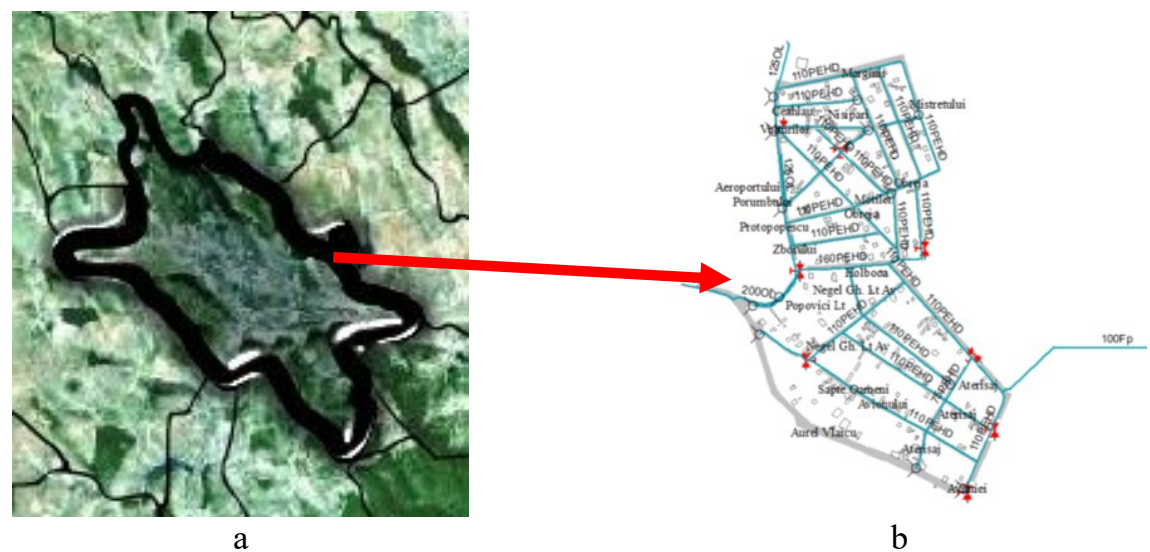

Fig. 4. Localization of the study area: $a$ - the city of Iasi; $b$ - Aviation Plate area.

The case study, drawn up in a sector of the city of Iaşi, "Aviation Plateau", highlights the current exploitation of the hydrant network and the rehabilitation opportunities. The "Aviation Plate" urban area is made up of main and secondary streets. The area is occupied with buildings, mainly residential, but also a small number of commercial spaces. The height predominant mode is $\mathrm{P}, \mathrm{P}+2 \mathrm{E}$. In the last 5 years, a series of buildings with height regime $\mathrm{P}+4 \mathrm{E}$ (private children's home) and $\mathrm{P}+10 \mathrm{E}$ (dwelling block) were built at the NE limit.

Several types of analyzes were made in the study area to social, economic, political, environmental and water network utility data.

a) Identification of hydrants and current analysis of the basic demand in water supply in case of fire.

Within the study area it was determined (by simulation in the Epanet program) that the fire base demand falls between $0.0261 / \mathrm{s}$ and $0.0521 / \mathrm{s}$. Thus, it can be seen that in areas where land has a higher share demand is higher. In the study area there is a significant difference (Fig. 5), with variations from $40.14 \mathrm{~m}$ in the south west to $69.71 \mathrm{~m}$ in the north

Hydrants identification and current status analysis by field research. The initial fire network was composed of 14 hydrants. As a result of the research carried out on the ground to check their state, in the years 2017-2018 the following were found:

- the hydrant with the H1 code located on Holboca Street was not identified on the ground (this should have been located on the sidewalk); 
- the hydrant with H2 code, located on Holboca Street, is located on the road, is not signaled, and the cover is covered with dry vegetation and paving slabs;

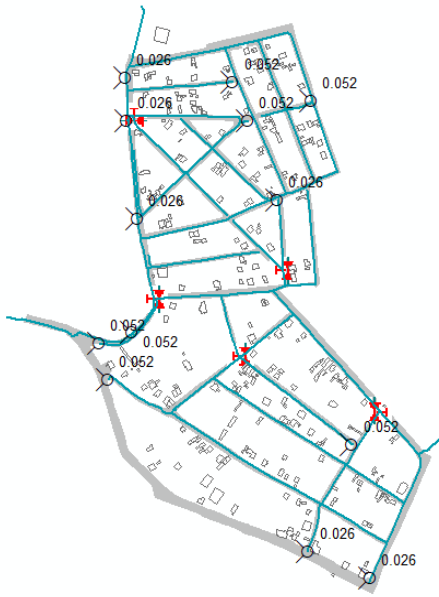

a

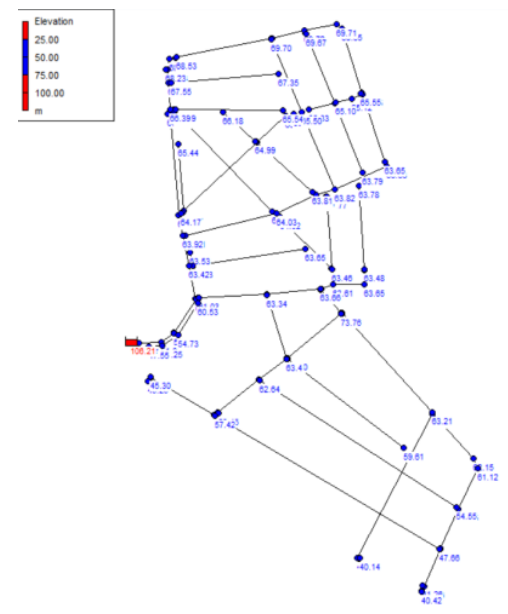

b

Fig. 5. Requirements analysis in the study area: a - water demand (1 / s); $\mathrm{b}$ - the plot of land $(\mathrm{m})$.

- the hydrant with the H3 code, located on the Airport Street, near the Porumb Street, is located in the area of some residential buildings with average height $\mathrm{P}+4 \mathrm{E}$, index $\mathrm{A}$ and low fire risk category;
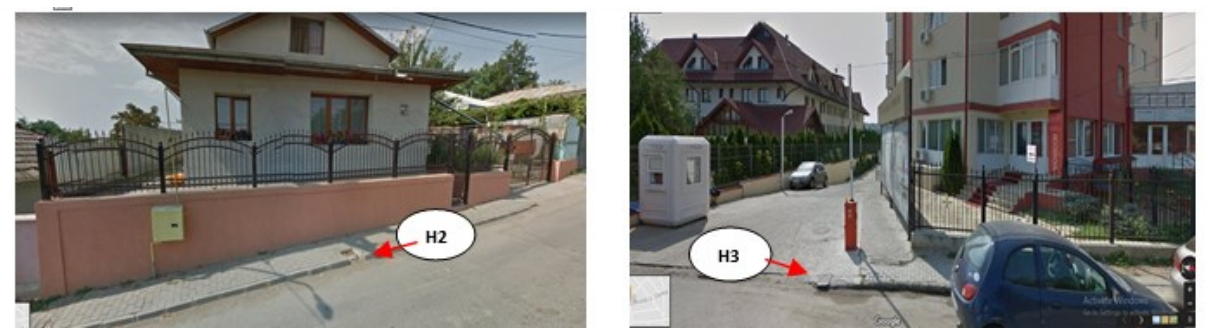

Fig. 6. Identification of hydrants with the code H2, H3, in the "Aviation Plate"

- the hydrant with the H4 code, located on the Airport Street, near the intersection with the Protopopescu and Vulturi streets, is positioned on the 
sidewalk and is marked accordingly; the hydrant has a diameter of $100 \mathrm{~mm}$, with a land area of $66.41 \mathrm{~m}$, and in its vicinity is a CIE type building, with a medium height $\mathrm{P}+1 \mathrm{E}$, with a mapping index $\mathrm{B}$ and a major risk in case of fire. The building is the headquarters of a company that works with paper, metal, plastic, wood, etc. (Fig. 6);

the hydrant with the H5 code, located on the Airport Street, was not identified on the ground;

- $\quad$ the hydrant with the H6 code, located on Ceahlău Street, is positioned on the sidewalk, but there has been a marked deterioration of the structure and the hydraulic installation; the H6 hydrant is partially covered with asphalt, so in the case of a fire, the layer must be removed beforehand, the operation impedes the firemen's task (fig. 7);
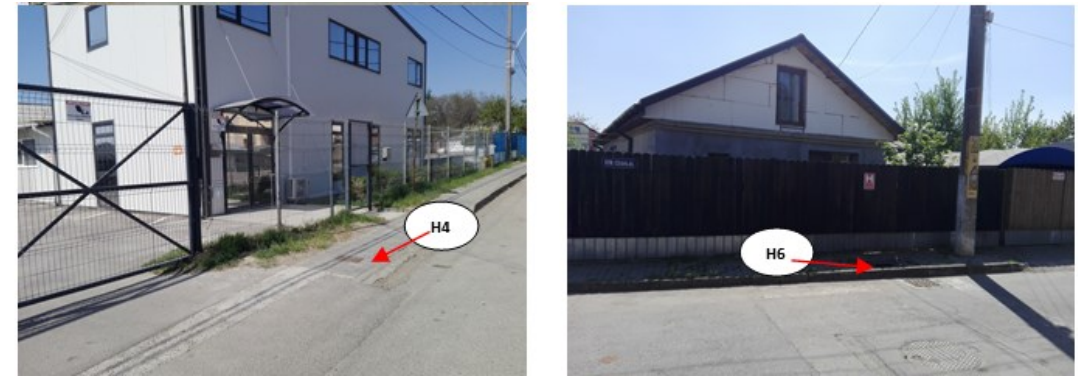

Fig. 7. Identification of hydrants with the code H4, H6 in the "Aviation Plate"

- the hydrant code H7, located on Porumbul Street, near the intersection with the Nisipari and Eagle streets, was not identified in the field; the field analysis shows (Fig. 8) the location where the H7 hydrant should have been placed and where only the signaling sign remained;

- the hydrant with the H8 code, is located on Marginii Street near the intersection with the streets of Obreja and Vulturi (secondary pebbled street); as with the $\mathrm{H} 7$ hydrant, it was not found in the field (only the signpost is in position);

- the hydrant with the H9 code, located on Moţi street near the intersection with the Obreja street, has a pavement location; the hydrant is partially degraded (no cover) and the sign is missing; the hydrant has a diameter of $100 \mathrm{~mm}$, with an area of 63,92 $\mathrm{m}$ and an application of 0,026 1/ $\mathrm{s}$;

- the hydrant with code H10, located on Aurel Vlaicu street near the intersection with Seven People Street, was not identified in the field; 

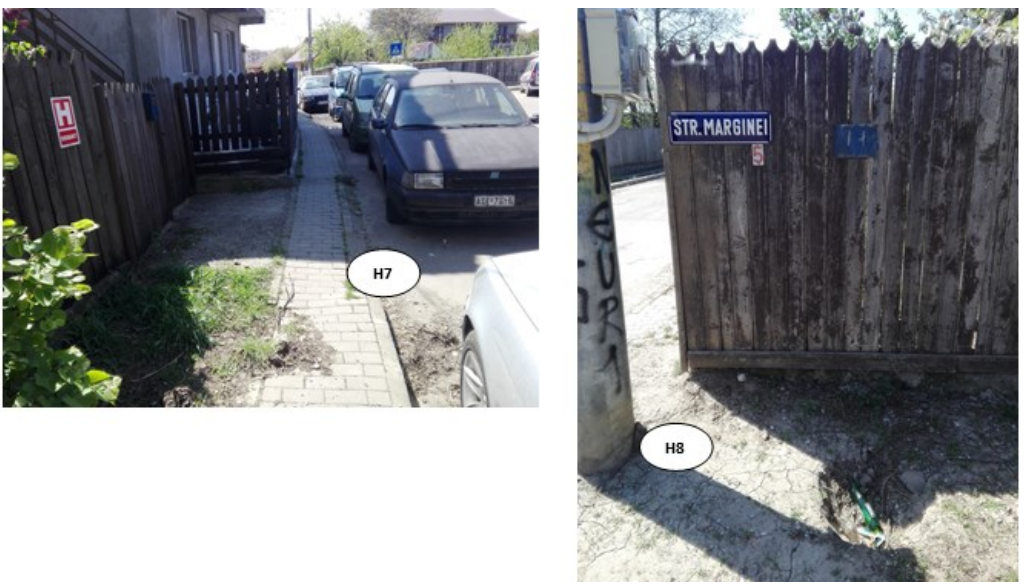

Fig. 8 Identification of hydrants with code H7, H8 in the area "Aviation Plate"

- the hydrant with the H11 code, located on Aurel Vlaicu Street near the intersection with Seven People Street, has its pavement location; the hydrant was canceled, and on the ground we only identified a part of its facility;
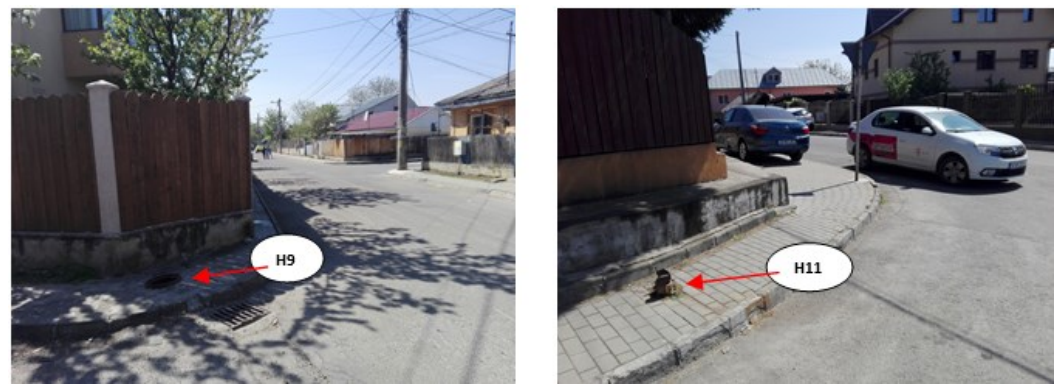

Fig. 9 Identification of hydrants with H9, H11 in the "Aviation Plate" area

- the hydrant with the H12 code, located on Aurel Vlaicu Street near the Aterisaj Street intersection, has the pavement location; the hydrant has a diameter of $100 \mathrm{~mm}$, with a $40.03 \mathrm{~m}$ terrain and a request of $0.0261 / \mathrm{s}$, it is not properly signposted and the cover is missing, so that the hydrant installation is accessible and can not be protected; the upper part of the hydrant is not maintained and the 
mark is provisional and can be removed; the hydrant is placed on a degraded pavement, which can lead to loss of stability over time;

- the hydrant with H13 code positioned on Negel Ghe Street. Lieutenant near the intersection with Aterisaj Street, it was not identified on the ground.

- the hydrant with the H14 code, located on Aviaţiei street near the intersection with Aurel Vlaicu Street, is located on the sidewalk near two CAS buildings; the hydrant has a diameter of $100 \mathrm{~mm}$, a ground rate of $41.26 \mathrm{~m}$ and a demand of $0.0261 / \mathrm{s}$, a non-existent signage marking.

From the field research, it emerged that of the 14 hydrants mentioned in the documents only eight hydrants were identified, one of which was canceled. By field research, the eight identified hydrants were found to have pavement location, not adequately signaled (H2, H9 hydrants), or signaling plate missing (hydrant H14). In the case of hydrants $\mathrm{H} 2, \mathrm{H} 6, \mathrm{H} 9, \mathrm{H} 12$ the state of degradation of the structure and of the hydraulic installation was found. Six hydrants were not identified in the field. For $\mathrm{H} 7$ and $\mathrm{H} 8$ hydrants, only the signaling plate was identified (Fig. 8).

The constructive and functional features of the hydrants were introduced into their GIS monitoring model. Based on these data, the simulation scenarios for controlling and extinguishing the external fire produced in the "Aviation Plateau" area (Lateş I. et all., 2018) were made. The scenarios for simulating the operation of the pipeline network with hydrants have indicated the unsatisfactory state of the fire extinguishing installations in the "Aviation Plate" area. Many areas in the inhabited area are hard to cover in the fire, with difficulty in feeding the fire machines and large distances between the hydrants. The hydrant network has to be rehabilitated and completed according to the situation in the field. When installing hydrants, the norms and provisions of the specialty regulations (NP 133-2013, P 118-99) must be observed.

For the study area, three simulation scenarios were developed that were run using the Epanet and ArcMap programs. The scenarios had the following theme (Lateş I, et al., 2018): scenario 1 - it followed the functioning of the pipeline network according to the initial fire hydrants, scenario 2 - it analyzed the functioning of the the hydrant pipeline network currently in operation and scenario 3 - it analyzed the operation of the pipeline network with the addition of additional hydrants according to the results obtained from Scenarios 1 and 2.

\section{Conclusions}

1. Identification of fire hydrants is of particular importance to fire intervention teams, a situation that must be present in the GIS pipeline monitoring model. 
2. Correlation of hydro-hydraulic and real-type information helps to good interpretation and analysis within the GIS model of disaster situations that can occur in populated centers.

3. The rehabilitation of the pipeline network with hydrants is a current necessity and should include the addition of additional hydrants in line with the current and prospective situation in the field as well as with the results of the field research.

4. The hydro-cadastral monitoring GIS model is of particular importance in simulating and forecasting disaster phenomena in populated or industrial centers.

\section{Bibliography}

AIIR, Manualul de instalaţii, Is - Instalaţii Sanitare. Editura Artecno, Bucureşti, 2002.

Cheng H., Hadjisophocleous G., The modeling of fire spread in buildings by Bayesian network, Fire Safety Journal, Volume 44, Issue 6, Pp. 901-908, 2009

Ferreiraa T.M., Vicente R., Raimundo Mendes da Silva J.A., Varum H., Costaa A., Maio R., Urban fire risk: Evaluation and emergency planning, Journal of Cultural Heritage, Volume 20, Pp. 739-745, 2016

Hogaș H., Tehnologii moderne în cadastru - Suport de curs, Iași, 2015

Lateș Iustina, Chirica Ștefania, Luca Al. L., 2018. Monitoring pipelines under pressure using GIS models. Proceedings of Danube-Eastern Europe Regional Water Forum, International Conference "Efficient use and management of water 2018", ARA Publishing, Bucureşti, p. 54-61, ISBN 978-973-88245-3-9.

Peştişanu C., Darie M., Voiculescu M., Vierescu R., Construcţii. Edit. Didact. şi Pedagog. Bucureşti, 1995.

Zhang X., Yao J., Sila-Nowicka K., Exploring Spatiotemporal Dynamics of Urban Fires:A Case of Nanjing, International Journal of Geo-Information, Volume 7, Issue 1, China, 2018

*** Legea 7/1996 - Legea cadastrului și a publicității imobiliare

*** NP 133-2013 Normativ privind proiectarea, execuţia şi exploatarea sistemelor de alimentare cu apă şi canalizare a localităţilor, vol. 1, Alimentare cu apă. Edit. Matrix-Rom, București, 2013

*** P118-1999 - Normativ de siguranţă la foc a construcţiilor

***P118/2-2013 - Normativ privind securitatea la incendiu a construcțiilor

*** SR EN 14339-2006 Hidranţi de incendiu subterani

*** SR EN 14384-2006 Hidranţi de incendiu supraterani

*** www.ancpi.ro 